\title{
Flow routing in mangrove forests: field data obtained in Trang, Thailand
}

\author{
E.M. Horstman ${ }^{1,2}$, C.M. Dohmen-Janssen ${ }^{1}$, T.J. Bouma ${ }^{2,3,4}$, S.J.M.H. Hulscher ${ }^{1}$ \\ ${ }^{1}$ Water Engineering and Management, University of Twente, P.O. Box 217, 7500 AE Enschede, The Netherlands. \\ E.M.Horstman@utwente.nl; C.M.Dohmen-Janssen@utwente.nl; S.J.M.H.Hulscher@utwente.nl \\ ${ }^{2}$ Singapore-Delft Water Alliance, National University of Singapore, Engineering Drive 2, 117576 Singapore. \\ ${ }^{3}$ Marine \& Coastal Systems, Deltares, P.O. Box 177, 2629 HD Delft, The Netherlands. \\ ${ }^{4}$ Netherlands Institute of Ecology, P.O. Box 140, 4400 AC Yerseke, The Netherlands. \\ T.Bouma@nioo.knaw.nl
}

\begin{abstract}
Mangroves grow in the intertidal parts of sheltered tropical coastlines, facilitating coastal stabilization and wave attenuation. Mangroves are widely threatened nowadays, although past studies have indicated their contribution to coastal safety. Most of these studies were based on numerical modeling however and a proper database with field observations is lacking yet. This paper presents part of the results of an extensive field campaign in a mangrove area in Trang Province, Thailand. The study area covers the outer border of an estuarine mangrove creek catchment. Data have been collected on elevation, vegetation, water levels, flow directions and flow velocities throughout this study area. Due to the tough conditions in the field, developing a suitable method for data collection and processing has been a major challenge in this study. Analysis of the hydrodynamic data uncovers the change of flow directions and velocities throughout a mangrove creek catchment over one tidal cycle. In the initial stages of flooding and the final stages of ebbing, creeks supply water to the lower elevated parts of the mangroves. In between these stages, the entire forest bordering the estuary is flooded and flow directions are perpendicular to the forest fringe. Flow velocities within the creeks are still substantially higher than those within the forest, as the creeks also supply water to the back mangroves. These insights in flow routing are promising for the future analysis of sediment input and distribution in mangroves.
\end{abstract}

\section{INTRODUCTION}

Mangroves form an indispensable ecosystem in the intertidal area of many tropical and sub-tropical coastlines. Mangrove vegetation consists of salt tolerant trees and shrubs, able to resist the hydrodynamic forces faced in the intertidal parts of sheltered coastlines such as estuaries and lagoons [Augustinus, 1995]. Due to their location and persistence, mangroves play an important role in coastal stabilization [Alongi, 2008; Augustinus, 1995; Furukawa and Wolanski, 1996; Krauss et al., 2003; Van Santen et al., 2007] and wave attenuation [Brinkman, 2006; Hong Phuoc and Massel, 2006; Mazda et al., 2006; Quartel et al., 2007]. Despite this key-function of mangroves in the intertidal area, they are in rapid decline. According to the most recent estimate of global mangrove area there is only 13.8 million ha [Giri et al., 2011] left of the 18.8 million ha of mangrove cover found worldwide in 1980 [FAO, 2007]. Hence since 1980 the mangrove area decreased by about $27 \%$ and although annual mangrove losses are slowing down, recent annual loss rates are still around $1 \%$ [Bosire et al., 2008; FAO, 2007]. Therefore there is an urgent need to unravel the contribution of mangroves to long-term coastal safety in order to increase awareness of the need for and hence the success of mangrove preservation.

To date, studies on water flows through mangrove systems are limited. Hydrodynamic studies into flow velocities focus on creekforest interactions and the consequent tidal asymmetry and selfscouring of tidal mangrove creeks [Aucan and Ridd, 2000; Furukawa et al., 1997; Mazda et al., 1995; Wolanski et al., 1980].
This issue gained interest quite a while ago, since flow routing is important for supply of e.g. sediment and nutrients to mangroves [Wolanski et al., 1980]. Most studies investigate mangrove hydrodynamics through numerical models, field data to calibrate and validate these models are sparse. Collection of field data is often limited in time and space; field campaigns usually last for a few days and often only one study site is taken into account [Aucan and Ridd, 2000; Furukawa et al., 1997; Kobashi and Mazda, 2005]. Comprehensive field studies into hydrodynamics within mangrove forests are really sparse [Mazda et al., 1997], although this information is highly relevant for the distribution of sediments throughout the mangrove area [Furukawa et al., 1997]. Mazda et al. [1997] and Kobashi \& Mazda [2005] only made a start by extending knowledge on water flowing through mangrove forests by collecting flow velocity data along transects through mangroves. This procedure is practiced more often for data collection on wave attenuation in mangroves [Brinkman, 2006; Vo-Luong and Massel, 2008]. Studies linking 2-dimensional flow routing through mangroves to gradients in elevation and vegetation are unprecedented.

A first step forward to increase our understanding of mangrove functioning is to collect an extensive hydrodynamic database in the field. Integrated measurements on elevation, vegetation, water levels, flow velocities and flow directions throughout a mangrove area are required to be able to unravel flow routing through mangroves. This short-paper aims to shed a light on the importance of tidal creeks, which are a common feature in mangroves, for transporting water into mangroves. 

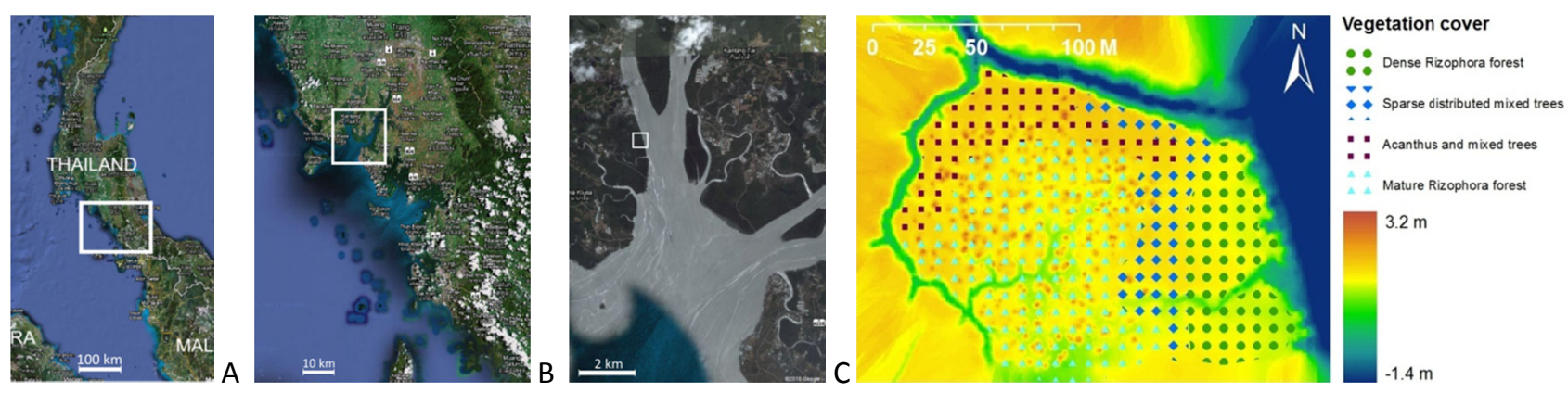

Figure 1. Geography of the study site: (A) Andaman coast of Thailand; (B) Trang province; (C) location off the study site in the Kantang River estuary near Kantang Tai village (opposite the river); (D) elevation and vegetation map of the studied creek catchment.

This paper presents field data obtained during a field campaign in a mangrove catchment in Trang Province, Thailand, from January to May 2011. Section 2 gives an introduction into the geography of this study site. Section 3 presents how hydrodynamic data are obtained within the study area. This section describes procedures for both data collection and data processing. Next, results of the data analysis are presented. These results will be discussed subsequently, leading to some preliminary conclusions following from the analysis of the obtained field data.

\section{STUDY SITE}

The study site $\left(7^{\circ} 19^{\prime} 45^{\prime \prime} \mathrm{N}\right.$; $\left.99^{\circ} 29^{\prime} 17^{\prime} \mathrm{E}\right)$ is located in the Kantang River estuary at the east coast of southern Thailand, in Trang Province (Figure 1A-C). This area is part of the convoluted Thai Andaman coast, consisting of many embayments, islands and islets offering a perfect habitat to mangroves. This paper focusses on data collected in part of a creek catchment directly bordering the Kantang River (Figure 1C). The study area is tide dominated [Woodroffe, 1992] being exposed to a mixed semi-diurnal tide with a tidal amplitude of $3.5 \mathrm{~m}$. The study area only covers part of the catchment fed by the main creek bordering the northern edge of the study area (Figure 1D) and forms the fringe of a much more extended mangrove forest extending about $1 \mathrm{~km}$ inland.

The geography of the study area has been mapped extensively with Trimble survey equipment (SPS 700-S6 Total Station and R6 Real Time Kinematic GPS). Obtained elevation data has been interpolated (ordinary kriging with exponential semivariogram model; $0.7 \mathrm{~m}$ resolution) and plotted with respect to a datum just in front of the forest fringe (N0 in Figure 3A) in Figure 1D. The study area shows a pronounced $1 \mathrm{~m}$ high cliff at the interface with the estuary. Elevation of the forest floor increases while moving further inland, although deep creeks penetrate far into the forest and show incisions bordered by distinct creek banks. The main creek in the north is over $2 \mathrm{~m}$ deep. While penetrating deeper into the forest, the creeks tend to get narrower and shallower and they end in a depression in the centre of the study area. The mounds in the sheltered centre and west of the study area are mud mounds built by mud lobsters.

Four distinct vegetation zones are mapped in-situ and are shown in Figure 1D as well. The forest fringe facing the Kantang river is densely covered with Rizophora trees. Directly behind this fringe, a less dense forest cover is found consisting of a mix of Rizophora, Avicennia, Sonneratia, Bruguiera and Xylocarpus trees. Along the main creeks in the study area the same mix of trees is observed with an understory of Acanthus shrubs. Rizophora trees are dominant in the inner part of the study area.

\section{METHODOLOGY}

\section{Data collection}

Flow velocities and directions have been monitored throughout the study area with Acoustic Doppler Velocimeters (ADV's, Nortek) with cable probes. ADV's turned out to be very suitable equipment for monitoring hydrodynamics in coastal wetlands [Horstman et al., 2011]. The ADV probes have been mounted downward looking, with one receiver aligned to the north, monitoring flow velocities at just $7 \mathrm{~cm}$ above the bed (Figure 2). With this configuration, the probes' sensors were located up to 23 $\mathrm{cm}$ above the bed so minimum water depths of $25 \mathrm{~cm}$ were required for data collection. End bells of the ADV's battery and memory housing contained pressure sensors and these were mounted to monitor at $7 \mathrm{~cm}$ above the substrate as well (Figure 2). Hydrodynamic data have been collected at $16 \mathrm{~Hz}$ with a burst length of 4096 samples (i.e. 256 s) and a burst interval of 1500 seconds (25 min). Three ADV's were installed during spring tide (due to the necessity of spring low tide for installation in some locations) and were deployed during an entire spring neap tidal cycle (i.e. 14 days) each time.

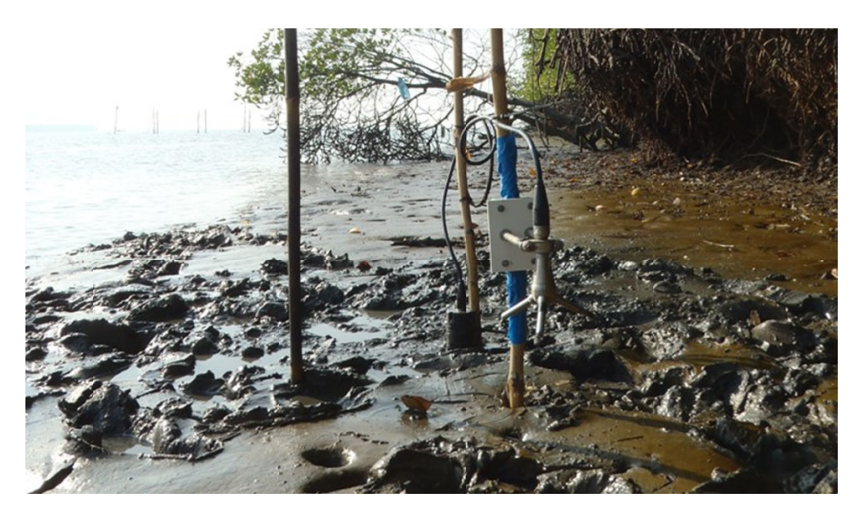

Figure 2. Acoustic Doppler Velocimeter during deployment in the field just in front of the mangrove fringe. Downward looking mounting to monitor flow velocities at $7 \mathrm{~cm}$ above the bed. Note the black canister in the back, containing the pressure sensor. 


\section{Data processing}

The output of each ADV deployment contains three velocity components, three correlation values and water pressure. These data have been averaged per burst and low quality data are removed by filtering for correlations lower than $70 \%$. Next, data series collected in four subsequent deployments (due to limited equipment availability) have been combined. ADV's were deployed such that every data series contained one common data collection point. Three data series contained velocities measured in the center of the study area (N3 in Figure 3A). From every data set for this central data collection point, data for one single tidal inundation have been selected showing equal inundation depths and flow velocities. Subsequently, concurrent measurements (internal clocks of the ADV's provided time stamps) have been selected for the surrounding data points from each series (K3 and L3, N0 and N1, N4 and O3 respectively). For the final data series, the reference data point was located in the main creek to the north instead (K3). One tidal peak was selected from these data to resemble inundation depths and velocity components of the representative tidal inundation as it was found before for this location. Then the timestamp of this tidal peak facilitated the selection of concurrent single tide data for the other two data collection points in the minor creeks to the west and south of the catchment (N5 and $\mathrm{P} 1$ respectively). By this procedure, threedimensional flow velocity data have been assembled for nine data points throughout the study area representing equal tidal conditions (tidal stage and amplitude).

\section{RESULTS}

Figure 3 presents the resulting temporal sequence of flow velocity patterns throughout the study area (positions are indicated in Figure 3A) for one tidal cycle for which the field data have been merged. High slack tide is around 23:40 h for this instance. Inflow in the main creek to the north of the study area is observed from around 17:30 $\mathrm{h}$ onwards, but was not observed at that time yet since the ADV in this creek was located off the thalweg (due to shipping). Data coverage starts at $19 \mathrm{~h}$, when the water depth at $\mathrm{K} 3$ exceeds the required minimum depth (i.e. $25 \mathrm{~cm}$ ). Figure 4 shows the development of the current velocities observed at K3. It shows that on the initial stages of flood (positive current velocities), within creek flow velocities are about $0.1 \mathrm{~m} / \mathrm{s}$ only. This rapidly changes on initiation of flooding of the mangroves. The lowest areas of the mangrove forest are located at about $1.6 \mathrm{~m}$ elevation (w.r.t. N0). When these areas start to inundate, suddenly large volumes of water need to be transported into the mangroves, causing a rapid increase in creek discharge and hence of within creek flow velocities. This situation is shown in figure $3 \mathrm{~B}$; water is transported through the creeks into the study area.

At the same instance, however, the mangroves also start to inundate directly from the forest fringe bordering the estuary. Within half an hour after initiation of flow velocity measurements at N3, a change in current directions is observed (see Figure 3C and Figure 4). Once the entire study area is inundated, including the bank separating the forest fringe from the central parts of the catchment, a uniform flow direction perpendicular to the forest fringe is observed. This indicates that water throughout the study area is flowing parallel to the main creek now and that it flows directly from the estuary into the forest. Flow velocities within the creeks stay significantly larger though, since huge quantities of water are required to inundate the extensive mangrove area located to the west of the studied area. Within creek water depths are larger and bottom friction within creeks is negligible compared to shear stresses experienced within the forest vegetation, facilitating the rapid supply of water to the back mangroves through these creeks.

When getting close to high tide, a rapid decrease of flow velocities throughout the study area is observed (Figure 3D) until slack tide. Figure $3 \mathrm{E}$ shows that at the turning of the tide, flow velocities throughout the study area have reversed towards the estuary already, while flow velocities observed within the creek are still directed to the west. This is caused by the fact that flow velocities have been monitored at $7 \mathrm{~cm}$ above the creek bed. Higher up in the water column at K3 (at levels exceeding the elevation of the forest floor), flow velocities turn concurrently with the flow velocities throughout the studied mangrove forest.

During ebb tide, the inverse sequence of events is observed as during flooding of the forest. Rapidly increasing negative flow velocities are observed on the initiation of ebb tide. Flow velocities throughout the study area are directed perpendicular to the forest fringe again, discharging directly into the estuary (Figure 3F\&G). Only in the final stages of ebbing from the forest a change in flow pattern is observed again, with water being discharged via the creeks towards the estuary (Figure $3 \mathrm{H}$ ).

Although current patterns at ebb and flood show a clear resemblance, current velocities do not. Figure 4 shows that creek flows only show a short-term peak flow velocity $(0.3 \mathrm{~m} / \mathrm{s}$ for this instance) during flood (only one data point, i.e. one burst), while flow velocities at ebb tide maintain a slightly lower maximum speed for a much longer duration (during five bursts). This is caused by a delayed discharge from the forest due to the high vegetation roughness faced by the tidal currents. On incoming tide, the same roughness hampers the inflow of water into the forest causing the delayed velocity peak after flooding of the forest at a water level of $1.6 \mathrm{~m}$. This sequence of flow velocities leads to self-scouring of the creeks, which has been observed in mangrove studies before [Mazda et al., 1995]. In contrary to this asymmetric pattern observed in tidal creek flows, within forest flows do not show such a distinct difference between inflow at flood and outflow at ebb tide (Figure 4).

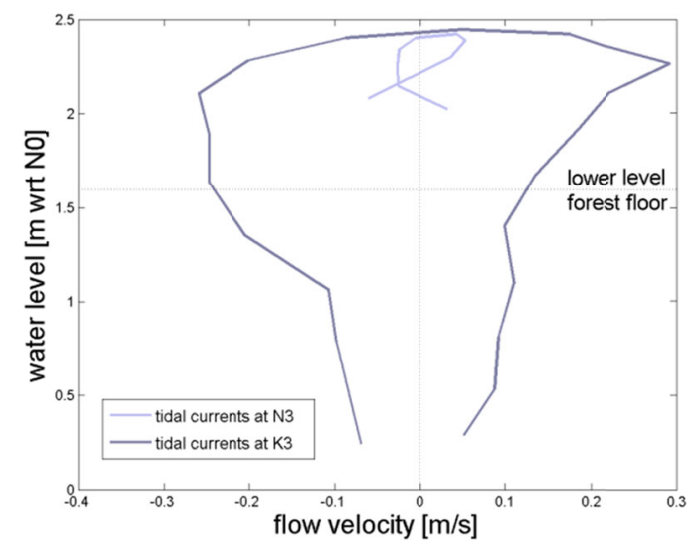

Figure 4. Current velocities observed within the creek (at K3) and in the center of the study area (N3). Velocities plotted are absolute magnitudes of the velocity vectors. Positive values are directed to the west, negative values to the east. The mangroves start to inundate at a water level of $1.6 \mathrm{~m}$. 

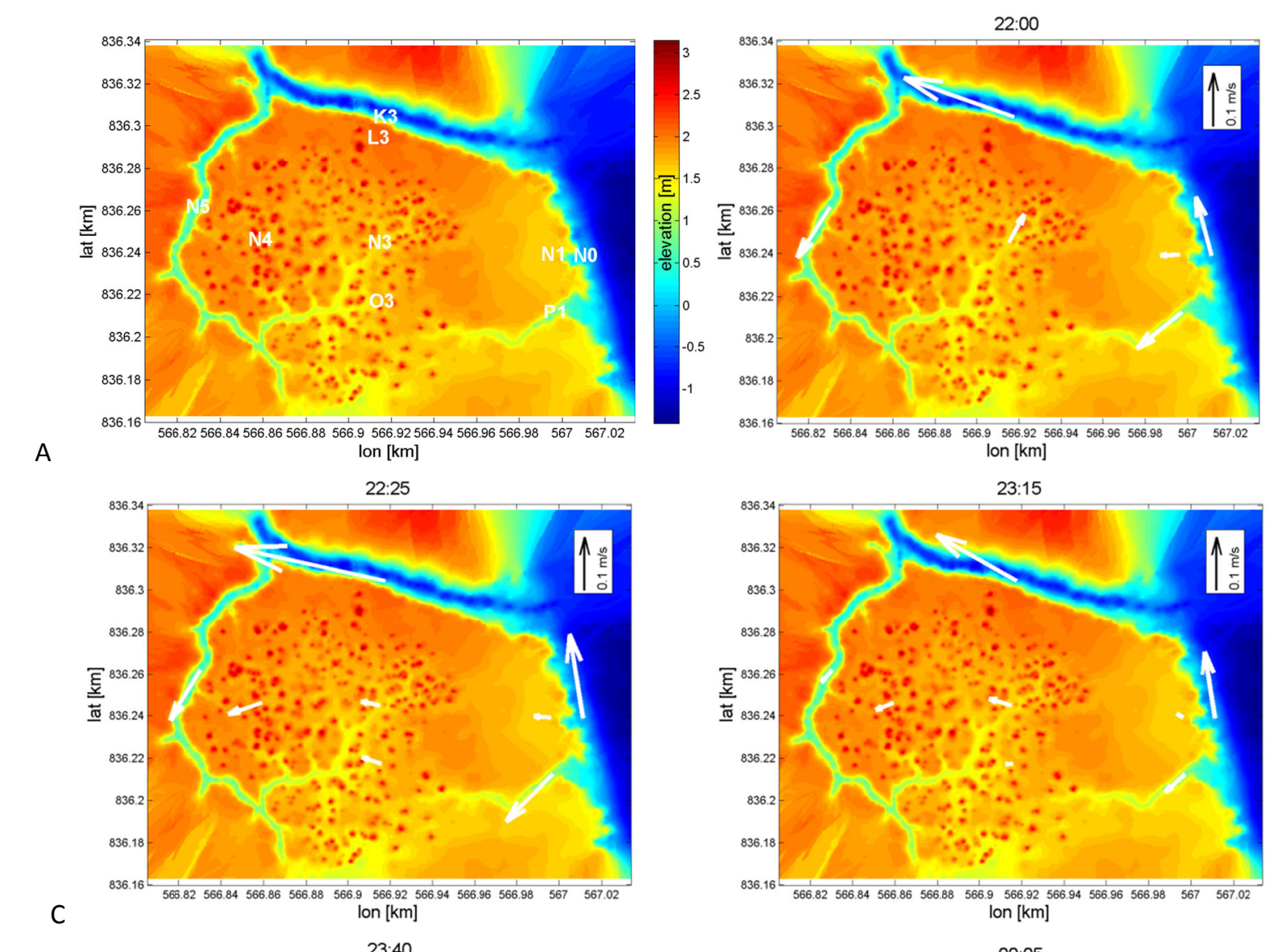

D
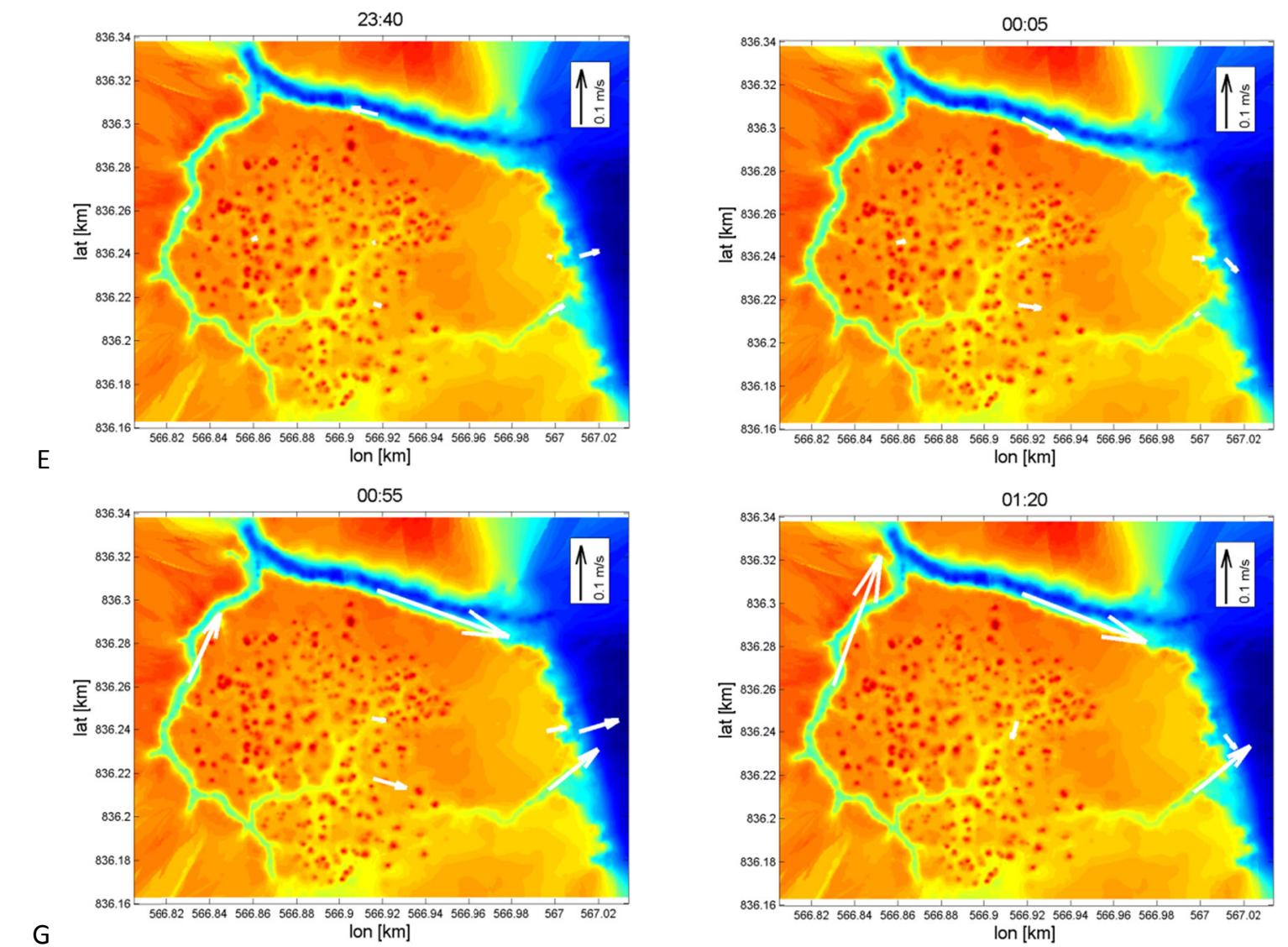

Figure 3. Nine positions for flow velocity measurements are indicated in (A). (B-H) Show the change of flow velocities and directions during an entire tidal cycle (slack high tide at 23:40), from the initial stages of filling of the area to full inundation and subsequent stages of discharge on outgoing tide. L3 does not inundate deeper than about $20 \mathrm{~cm}$ and hence flow velocities could not be measured. 


\section{DISCUSSION}

Although tidal flow patterns through the studied mangrove area are unraveled by showing the flow velocities at different stages of flooding and ebbing, there is no clear-cut conclusion about the importance of tidal creeks in filling and emptying of the mangroves yet. Flow velocities presented in this paper only describe the situation at $7 \mathrm{~cm}$ above the bed. This velocity does at first not represent the velocity throughout the entire water column (as near bed flow velocities are significantly lower than those higher up in the water column). Measuring flow velocities at higher levels would have been of little use however as in these cases required water depths for proper ADV functioning would hardly ever occur. Next, it was shown that in the creeks not even the direction of the water current is per se the same throughout the entire water column. So the present analysis does not yet quantify the contribution of creeks to mangrove hydrodynamics.

\section{CONCLUSIONS}

The preliminary analysis presented in this paper underlines that creeks are mainly important for the initial stages of tidal filling and final stages of tidal emptying of the mangroves. The near-bed flow velocities presented here are valuable information for the future analysis of sediment transport through mangroves. Concurrently measured suspended sediment concentrations will be related to these flow velocities, so to increase knowledge on sediment routing and deposition in mangroves.

\section{ACKNOWLEDGEMENTS}

The authors gratefully acknowledge assistance in planning, facilitating and executing fieldwork by M. Siemerink (University of Twente), N.J.F. van den Berg (University of Twente), D. Galli (National University of Singapore), T. B alke (Deltares/SingaporeDelft Water Alliance), D.A. Friess (National University of Singapore/Singapore-Delft Water Alliance), E.L Webb (National University of Singapore), C. Sudtongkong (Rajamangala University of Technology Srivijaya), Katai, Dumrong and Siron. Fieldwork for this paper has been executed under the NRCT research permit 'Ecology and Hydrodynamics of Mangroves' (Project ID-2565). Also gratefully acknowledged is the support \& contributions of the Singapore-Delft Water Alliance (SDWA). The research presented in this work was carried out as part of the SDWA's Mangrove research program (R-264-001-024-414).

\section{REFERENCES}

Alongi, D. M. (2008), Mangrove forests: Resilience, protection from tsunamis, and responses to global climate change, Estuar. Coast. Shelf Sci., 76(1), 1-13.

Aucan, J., and P. V. Ridd (2000), Tidal asymmetry in creeks surrounded by saltflats and mangroves with small swamp slopes, Wetlands Ecology and Management, 8(4), 223-232.

Augustinus, P. G. E. F. (1995), Geomorphology and sedimentology of mangroves, in Developments in Sedimentology, edited by G. M. E. Perillo, pp. 333-357, Elsevier.

Bosire, J. O., F. Dahdouh-Guebas, M. Walton, B. I. Crona, R. R. Lewis Iii, C. Field, J. G. Kairo, and N. Koedam (2008),
Functionality of restored mangroves: A review, Aquatic Botany, 89(2), 251-259.

Brinkman, R. M. (2006), Wave attenuation in mangrove forests: an investigation through field and theoretical studies, $\mathrm{PhD}$ thesis, 146 pp, James Cook University, Townsville.

FAO (2007), The world's mangroves, 1980-2005., 77 pp., Food and Agriculture Organization of the United Nations, Rome.

Furukawa, K., and E. Wolanski (1996), Sedimentation in Mangrove Forests, Mangroves and Salt Marshes, 1(1), 3-10.

Furukawa, K., E. Wolanski, and H. Mueller (1997), Currents and sediment transport in mangrove forests, Estuar. Coast. Shelf Sci., 44(3), 301-310.

Giri, C., E. Ochieng, L. L. Tieszen, Z. Zhu, A. Singh, T. Loveland, J. Masek, and N. Duke (2011), Status and distribution of mangrove forests of the world using earth observation satellite data, Glob. Ecol. Biogeogr., 20(1), 154159.

Hong Phuoc, V. L., and S. R. Massel (2006), Experiments on wave motion and suspended sediment concentration at Nang Hai, Can Gio mangrove forest, Southern Vietnam, Oceanologia, 48(1), 23-40.

Horstman, E., T. Balke, T. Bouma, M. Dohmen-Janssen, and S. Hulscher (2011), Optimizing methods to measure hydrodynamics in coastal wetlands: evaluating the use and positioning of ADV, ADCP AND HR-ADCP.

Kobashi, D., and Y. Mazda (2005), Tidal Flow in Riverine-Type Mangroves, Wetlands Ecology and Management, 13(6), 615619.

Krauss, K. W., J. A. Allen, and D. R. Cahoon (2003), Differential rates of vertical accretion and elevation change among aerial root types in Micronesian mangrove forests, Estuar. Coast. Shelf Sci., 56(2), 251-259.

Mazda, Y., N. Kanazawa, and E. Wolanski (1995), Tidal asymmetry in mangrove creeks, Hydrobiologia, 295(1), 51-58.

Mazda, Y., M. Magi, Y. Ikeda, T. Kurokawa, and T. Asano (2006), Wave reduction in a mangrove forest dominated by Sonneratia sp., Wetlands Ecology and Management, 14(4), 365378.

Mazda, Y., E. Wolanski, B. King, A. Sase, D. Ohtsuka, and M. Magi (1997), Drag force due to vegetation in mangrove swamps, Mangroves and Salt Marshes, 1(3), 193-199.

Quartel, S., A. Kroon, P. G. E. F. Augustinus, P. Van Santen, and N. H. Tri (2007), Wave attenuation in coastal mangroves in the Red River Delta, Vietnam, J. Asian Earth Sci., 29(4), 576-584.

Van Santen, P., P. Augustinus, B. M. Janssen-Stelder, S. Quartel, and N. H. Tri (2007), Sedimentation in an estuarine mangrove system, J. Asian Earth Sci., 29(4), 566-575.

Vo-Luong, P., and S. Massel (2008), Energy dissipation in nonuniform mangrove forests of arbitrary depth, J. Mar. Syst., 74(12), 603-622.

Wolanski, E., M. Jones, and J. Bunt (1980), Hydrodynamics of a tidal creek-mangrove swamp system, Mar. Freshw. Res., 31(4), 431-450.

Woodroffe, C. D. (1992), Mangrove sediments and geomorphology, in Tropical mangrove ecosystems, edited by A. I. Robertson and D. M. Alongi, p. 329, American Geophysical Union, Washington DC. 